\title{
Genetic underpinnings of sociability in the UK Biobank
}

\author{
Bralten $J^{* 1}$, Klemann $\mathrm{CJHM}^{* 1}$, Mota $\mathrm{NR}^{* 1}$, De Witte $\mathrm{W}^{1}$, Arango $\mathrm{C}^{2}$, Fabbri $\mathrm{C}^{3}$, Kas $\mathrm{MJ}^{4}$, van der Wee \\ $\mathrm{N}^{5}$, Penninx BWJH ${ }^{6}$, Serretti $A^{3}$, Franke $B^{1,7 *}$, Poelmans $\mathrm{G}^{1 *}$ \\ $\left[{ }^{*}\right.$ equal contribution] \\ 1. Department of Human Genetics, Donders Institute for Brain, Cognition and Behaviour, Radboud \\ University Medical Center, Nijmegen, the Netherlands.
}

2. Institute of Psychiatry and Mental Health. Department of Child and Adolescent Psychiatry, Hospital General Universitario Gregorio Marañón School of Medicine, Universidad Complutense, Instituto de Investigación Sanitaria Gregorio Marañón (IISGM), CIBERSAM, Madrid, Spain.

\section{Department of Biomedical and NeuroMotor Sciences, University of Bologna, Italy}

4. Groningen Institute for Evolutionary Life Sciences, University of Groningen, the Netherlands.

5. Department of Psychiatry, Leiden Institute for Brain and Cognition/Psychiatric Neuroimaging, Leiden University Medical Center, the Netherlands

\section{Department of Psychiatry, Amsterdam University Medical Center/GGZ in Geest, Amsterdam, The} Netherlands

7. Department of Psychiatry, Donders Institute for Brain, Cognition and Behaviour, Radboud University Medical Center, Nijmegen, the Netherlands; Department of Cognitive Neuroscience, Donders Institute for Brain, Cognition and Behaviour, Radboud University Medical Center, Nijmegen, the Netherlands

\section{ABSTRACT}

Difficulties with sociability include a tendency to avoid social contacts and activities, and to prefer being alone rather than being with others. While sociability is a continuously distributed trait in the population, decreased sociability represent a common early manifestation of multiple neuropsychiatric disorders such as Schizophrenia (SCZ), Bipolar Disorder (BP), Major Depressive Disorder (MDD), Autism Spectrum Disorders (ASDs), and Alzheimer's disease (AD). We aimed to investigate the genetic underpinnings of sociability as a continuous trait in the general population. In this respect, we performed a genome-wide association study (GWAS) using a sociability score based on 4 social functioning-related self-report questions in the UK Biobank sample $(n=342,461)$ to test the effect of individual genetic variants. This was followed by LD score analyses to investigate the genetic correlation with psychiatric disorders (SCZ, BP, MDD, ASDs) and a neurological disorder (AD) as well as related phenotypes (Loneliness and Social Anxiety). The phenotypic data indeed showed that the sociability score was decreased in individuals with ASD, (probable) MDD, BP and SCZ, but not in individuals with AD. Our GWAS showed 604 genome-wide significant SNPs, coming from 18 independent loci (SNP-based h2 $=0.06$ ). Genetic correlation analyses showed significant correlations with SCZ ( $r g=0.15, p=9.8 e-23), \operatorname{MDD}(r g=0.68, p=6.6 e-248)$ and ASDs ( $r g=0.27, p=4.5 e-28)$, but no correlation with $\mathrm{BP}(\mathrm{rg}=0.01, \mathrm{p}=0.45)$ or $\mathrm{AD}(\mathrm{rg}=0.04, \mathrm{p}=0.55)$. Our sociability trait was also genetically correlated with Loneliness ( $r g=0.45, p=2.4 e-8)$ and Social Anxiety ( $r g=0.48, p=0.002)$. Our study shows that there is a significant genetic component to variation in population levels of sociability, which is relevant to some psychiatric disorders (SCZ, MDD, ASDs), but not to $B P$ and $A D$. 


\section{INTRODUCTION}

Sociability, the quality or state of inclining to seek or enjoy companionship, is a human trait which shows significant variability and is continuously distributed in the general population (ReebSutherland, Levitt, \& Fox, 2012). Difficulties with this trait include a tendency to avoid social contacts and activities, and to prefer being alone rather than being with others, potentially linked with a desire to avoid social embarrassment and has been associated with risks of adverse physical and mental health outcomes (Cacioppo, Grippo, London, Goossens, \& Cacioppo, 2015; Holt-Lunstad, Smith, Baker, Harris, \& Stephenson, 2015) including psychiatric disorders and neurological disorders (Addington, Penn, Woods, Addington, \& Perkins, 2008; Bora \& Berk, 2016; Dickerson, 2015; Wilson et al., 2007). Avoiding social contacts is an aspect frequently observed in autism spectrum disorders (ASDs), where persistent deficits in social communication and social interaction is one of the core deficits (Lord, Elsabbagh, Baird, \& Veenstra-Vanderweele, 2018). Additionally, social withdrawal is a common feature in Major Depressive Disorder (MDD)(Bora \& Berk, 2016; Kupferberg, Bicks, \& Hasler, 2016), SChiZophrenia (SCZ)(Addington \& Addington, 2008; Galderisi, Mucci, Buchanan, \& Arango, 2018; Green, Horan, \& Lee, 2015) and BiPolar disorder (BP)(Filizer, Cerit, Tuzun, \& Aker, 2016) and also observed in neurological disorders like Alzheimer's disease (AD)(Dickerson, 2015; Reichman \& Negron, 2001; Winograd-Gurvich, Fitzgerald, Georgiou-Karistianis, Bradshaw, \& White, 2006). Difficulties in sociability can therefore potentially be seen as a cross-disorder overlapping trait in these frequently co-occurring disorders (i.e. (Chisholm, Lin, Abu-Akel, \& Wood, 2015; Lee \& Lyketsos, 2003; Rai et al., 2018)) with potentially shared underlying mechanisms relating them. The withdrawal from friends, family, and colleagues, is one of the symptoms that is particularly burdensome for relatives of those affected by such disorders. Interestingly this withdrawal from social events and social relationships is one of the earliest signs of disease in groups of patients, suggesting it to be a potential target phenotype for early preventive intervention (Cross, Scott, \& Hickie, 2017; Nelis et al., 2011).

Psychiatric and neurological disorders that share difficulties with sociability as a common feature are known to be heritable (estimates are $~ 64-91 \%$ for ASD (Sandin et al., 2017), 30-40\% for MDD (Sullivan, Neale, \& Kendler, 2000), 79\% for SCZ (Hilker et al., 2018), 60\% for BP (Johansson, KujaHalkola, Cannon, Hultman, \& Hedman, 2019), 60-80 for AD (Gatz et al., 2006). Genome-wide association studies (GWAS) are the current gold standard for localizing common genetic risk variants important for these disorders, comparing people with the disorder (cases) to people without the disorder (controls). Results have been mixed, and extremely large sample sizes were needed to find robust genetic risk variants (ASD: $n=18381$ cases and 27969 controls, 5 loci (Grove et al., 2019), MDD: $n=246363$ cases and 561190 controls, 102 loci (D. Howard et al., 2019), SCZ: $n=36,989$ cases and 113,075 controls, 108 loci (Ripke et al., 2014), BP: $n=20,352$ cases and 31,358 controls, 30 loci (Stahl et al., 2019), AD: n=71,880 AD and AD-by-proxy and 383378 controls, 29 loci (Jansen et al., 2019)). A limitation in the case control design of these studies is the well-known phenotypic heterogeneity observed in these disorders, therefore 'cases' can consist of individuals with very diverse sets of symptoms, severity and clinical course. Next to that, comorbidity between disorders and overlap in symptomatology between disorders makes it difficult to select a group of 'cases' that includes just one disorder. This makes it, despite the high prevalence of these disorders, difficult to select cases for which genetic material for GWAS is available. Additionally, recent genetic evidence from the Brainstorm Consortium shows that psychiatric disorders share common genetic risk factors (Anttila et al., 2018) and diagnostic criteria do not follow the underlying biology of these disorders well. Investigating the genetics of common overlapping symptoms between disorders might therefore be a good approach to understand the underlying biological mechanisms involved in these disorders, and the co-morbidity of disorders.

Sociability is a multi-determined complex behaviour, which can be modulated by several factors - such as, among others, temperament, personality traits, disability status, aging, social environment and 
socio-economic status (Holt-Lunstad et al., 2015). There is also growing evidence that, at least in part, sociability is an independent behavioural trait with a specific biological substrate at its basis (Bellack et al., 2004; Kitamura \& Suga, 1991; Reichman \& Negron, 2001). Indeed the aspects that compose sociability, like loneliness and social interaction have been shown to be moderately to highly heritable by twin and family studies (Boomsma, Cacioppo, Slagboom, \& Posthuma, 2006; Boomsma, Willemsen, Dolan, Hawkley, \& Cacioppo, 2005; Distel et al., 2010; Ordonana et al., 2013; Stein et al., 2017). Genome-wide association studies investigating the influence of common genetic risk factors involved in loneliness (Gao et al., 2017) and social interaction and isolation (Day, Ong, \& Perry, 2018) indeed showed their involvement as well as genetic links to depressive symptoms. However, to our knowledge the underlying biological basis of sociability, as a composed construct including loneliness, social interaction, social isolation and social embarrassment is still to be identified and may differ between diseases, but also between diseases and healthy subjects that manifest this trait.

With difficulties in sociability being a common feature of multiple disorders (Kas et al., 2019; Porcelli et al., 2019), being distributed throughout the population and having a biological basis, studying the genetic underpinnings of sociability in the general population can be an elegant alternative way to study the genetics of overlapping symptoms. The recent increase in genotyped population cohorts, in particular the UK Biobank (Bycroft et al., 2018; Sudlow et al., 2015), increased GWAS sample sizes to hundreds of thousands of individuals. These sample sizes provide the statistical power to detect genetic variants with small effect sizes that are likely to contribute to complex phenotypes, like sociability. In the current study we aim to investigate the genetic contribution to sociability in the general population and if there is a genetic link to the psychiatric disorders ASD, MDD, BP and SCZ as well as the neurological disorder AD. In this light we studied an aggregated construct composed of four sociability-related self-reported questions in the UK Biobank sample and investigated single variant genetic association as well as phenotypic and genetic overlap with the aforementioned disorders. 


\title{
METHODS
}

\author{
Subjects
}

The UK Biobank (UKBB) is a major population-based study, which includes more than 500,000 individuals aged between 37 and 73 years. The initial data is collected between 2006 and 2010 and includes questionnaire data, genetic data and neuroimaging data. The study design and sample characteristics of the UK Biobank (UKBB) (http://www.ukbiobank.ac.uk/about-biobankuk/) have been extensively described elsewhere (Bycroft et al., 2018; Sudlow et al., 2015). The UKBB was approved by the National Research Ethics Service Committee North West Multi-Centre Haydock and all participants provided written informed consent to participate in the study.

\section{Sociability phenotype}

Four questions in the UK Biobank questionnaire were selected based on their link to sociability (1. Frequency of friend / family visits, 2. Leisure /social activities, 3. Worry after social embarrassment, 4. Loneliness). Based on the answers to these four questions we constructed a sociability measure, where the total score per participant is a sum of the scores on the questions. The sociability score was scored in such a way that a higher score indicated more difficulties with sociability (see Supplement 1). Participants were excluded if they had gross somatic problems which could be related to social withdrawal (BMI $<15$ or $\mathrm{BMI}>40$, narcolepsy (all the time), stroke, tinnitus, deafness or brain related cancers) or if they answered that they had "No friends/family outside household" to the question in data-field 'frequency of family/friends visit' or "Do not know" or "Prefer not to answer" to any of the questions. We grouped individuals with psychiatric and neurological disorders of interest. For MDD individuals were grouped by 'probable MDD' and the occurrence of 'Recurrent Depressive Episodes' (D. M. Howard et al., 2018), for SCZ individuals were grouped that had a Schizophrenia diagnosis, for AD individuals were grouped with an Alzheimer diagnosis, for Autism Spectrum Disorders (ASD) individuals were grouped that had childhood autism, atypical autism or Asperger, and for Bipolar Disorder (BP) all individuals that had a Bipolar Disorder diagnosis were grouped. Mean values and distributions were calculated per group using SPSS and compared between individuals with and without neuropsychiatric disorders using general linear models (correcting for age, sex, and assessment center).

\section{SNP genotyping and quality control}

Genotyping details for UKBB participants have been reported previously (Bycroft et al., 2018). Briefly, 49,950 participants were genotyped using the UK BiLEVE Axiom Array and 438,427 participants were genotyped using UK Biobank Axiom Array. The Haplotype Reference Consortium (HRC) and UK10K was the imputation reference sample. For ethnicity we selected self-reported "white" ancestry and subsequently performed a PCA analyses projecting the UKBB participants onto the 1000 Genome Project principal component coordination and excluded individuals that fell out of the cluster (based on PC1 and PC2). Genetic relatedness was calculated with KING kinship

(https://kenhanscombe.github.io/ukbtools/articles/explore-ukb-data.html and http://www.ukbiobank.ac.uk/wpcontent/uploads/2014/04/UKBiobank genotyping QC documentation-web.pdf) to identify first and second-degree relatives and subsequently 'families' were created and only one individual from created 'families' was included on the analysis. Single nucleotide polymorphisms (SNPs) with minor allele frequency $<0.005$, Hardy-Weinberg equilibrium test $P$ value $<1 \times 10-6$, missing genotype rate $>0.05$ and imputation quality of INFO $<0.8$ were excluded. In the current study 342.461 participants of European ancestry with both genotype and sociability scores available were selected for further analysis. 


\section{Genome-wide association analysis}

Genome-wide association analysis with the imputed marker dosages was performed in PLINK using a linear regression model with the sociability measure as the dependent variable and including sex, age, 10 PCA's, assessment center and genotype batch as covariates. Robustness analyses were included by running five split-half validation analyses splitting our sample five times in two equally sized groups and comparing single variant results as well as excluding individuals with known psychiatric and neurological disorders. Genome-wide association analyses on the four single questions that comprise our sociability score was performed using linear and logistic regression models correcting for sex, age, 10 PCAS, assessment center and genotype batch. To assess the proportion of phenotypic variance explained by common variants, we applied LD score regression (https://github.com/bulik/ldsc) that estimates heritability attributable to genome-wide SNPs (SNP-based heritability) from our sociability GWAS summary statistics based on the slope of the LD score regression (B. Bulik-Sullivan et al., 2015; B. K. Bulik-Sullivan et al., 2015).

\section{Genetic correlation analyses}

To evaluate the extent of shared common variant genetic architectures between sociability and SCZ, BP, MDD, ASD and AD (Grove et al., 2019; Lambert et al., 2013; Ripke et al., 2014; Stahl et al., 2019; Wray et al., 2018), as well as the traits loneliness and social anxiety (Gao et al., 2017; Stein et al., 2017), the bivariate genetic correlations attributable to genome-wide SNPs ( $\mathrm{rg}$ ) were calculated using LD score regression. The GWAS summary statistics underwent additional filtering steps. Only markers overlapping with HapMap Project Phase 3 SNPs and passing the INFO score $\geq 0.9$ and MAF $\geq 0.01$ filters were included (where available). SNPs with missing values, duplicate rs-numbers, too low a sample size (where available SNPs with an effective sample size less than 0.67 times the $90^{\text {th }}$ percentile of sample size were removed), or that were strand-ambiguous - as well as indels - were removed. We used precalculated LD scores ('eur_w_Id_chr/' files; (Finucane et al., 2015)) for each SNP using individuals of European ancestry from the 1000 Genomes project that are suitable for LD score analysis in European populations. 


\section{RESULTS}

Sociability measure

A total of 342.461 adults participants from the UK Biobank complied with the inclusion criteria for our study. The sociability score of all participants is distributed from 0-4, with a mean of 1.3 (see Supplement 2). Participants with a psychiatric disorder have a higher mean sociability score than the not affected group (ASD $p<0.001, \mathrm{BP}<0.001$, Probable MDD $p<0.001$, Recurrent Depressive Episodes $\mathrm{p}<0.001$, SCZ $\mathrm{p}<0.001$ ), but there was no significant difference between the unaffected group and people with an AD diagnosis ( $p=0.35)$ (Figure 1 ).

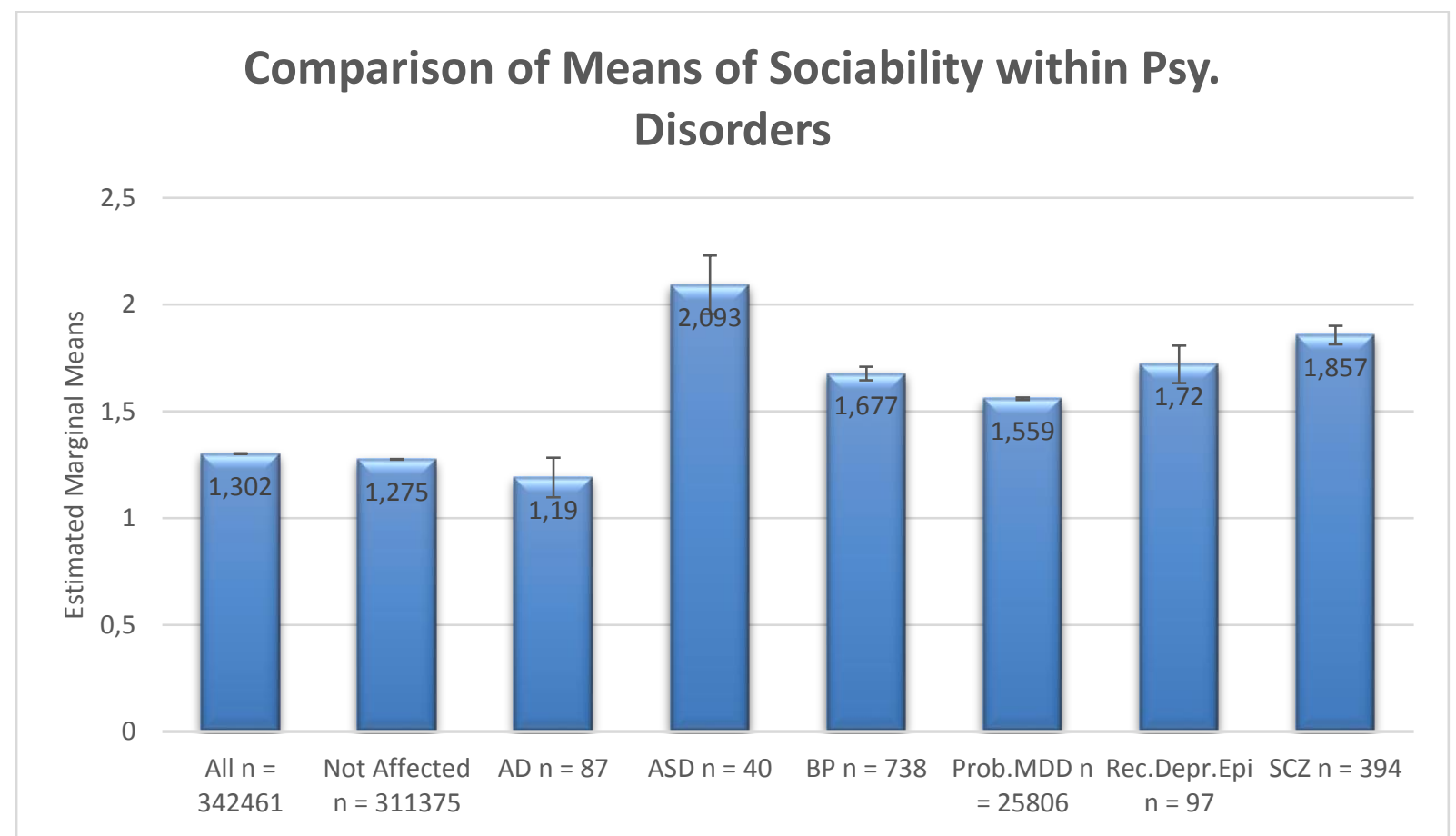

Figure 1: Mean sociability scores in the complete sample ('All'), individuals without psychiatric and neurological disorders ('Not Affected') and with specific disorders of interest (For Alzheimer's disease (AD) individuals were grouped with an Alzheimer's diagnosis, for Autism Spectrum Disorders (ASD) individuals were grouped that had childhood autism, atypical autism or Asperger, for Bipolar Disorder (BP) all individuals that had a Bipolar Disorder diagnosis were grouped, for Major Depressive Disorder (MDD) individuals were grouped by 'probable MDD' and the occurrence of 'Recurrent Depressive Episodes' (Rec. Depr. Epi.), for Schizophrenia (SCZ) all individuals that had a Schizophrenia diagnosis were grouped.

Genome-wide association analysis

Figure 2 shows the results of our genome-wide association analyses on the sociability score. In total 604 genetic variants in 18 loci, with 19 lead SNPs surpassed the threshold for genome-wide significance $(p<5 * 10-8)$ (Table 1). Our split-half validation showed that all variants had robust associations, showing nominally significant association in all five iterations. Excluding individuals with psychiatric and neurological disorders did not change the results. Single question GWASs showed that all single variant associations had nominal significance in at least two questions. We found that our sociability measure had a SNP-based heritability of 0.0574 (se=0.0025). 


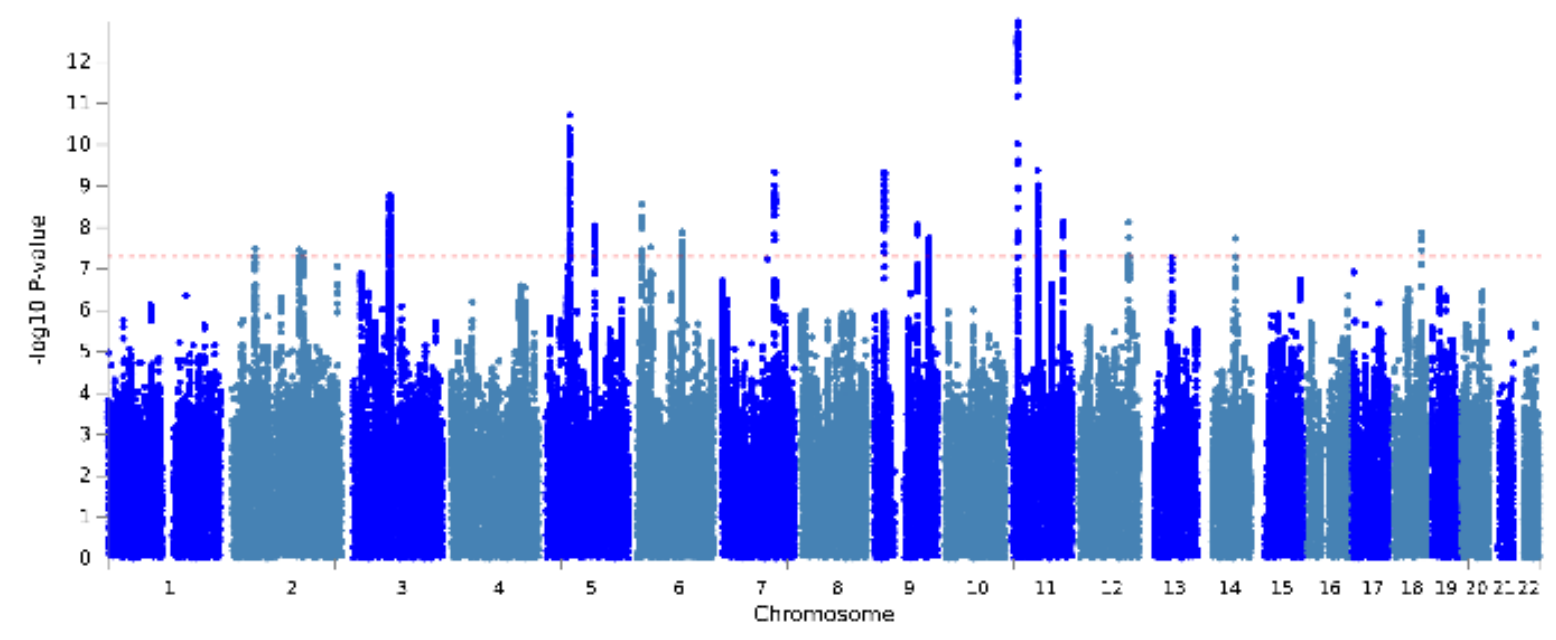

Figure 2: Manhattan plot of the genome-wide association analysis on the sociability construct in the Uk Biobank sample. Every dot indicates the outcome of the linear regression analysis of one single genetic variant with the sociability measure as the dependent variable and including sex, age, 10 PCA's, assessment center and genotype batch as covariates. On the x-axis you can find the chromosomes, on the $y$-axis you can find the -log 10 association p-value. The red dotted line indicates the threshold for genome-wide significance.

\begin{tabular}{|c|c|c|c|c|c|c|c|}
\hline leadSNP & chr & pos & p-value & Loci & start & end & nearestGene \\
\hline rs10180695 & 2 & 51292332 & 3,19986E-08 & 1 & 51203466 & 51306745 & AC007682.1 \\
\hline rs202220108 & 2 & 148910423 & 3,39779E-08 & 2 & $1,49 E+08$ & $1,49 E+08$ & MBD5 \\
\hline rs57601252 & 2 & 157100293 & $4,08658 \mathrm{E}-08$ & 3 & $1,57 E+08$ & $1,57 E+08$ & NR4A2 \\
\hline rs4266214 & 3 & 82003207 & 1,61066E-09 & 4 & 81630790 & 82402319 & RP11-359D24.1 \\
\hline rs62365541 & 5 & 50905846 & $1,93203 \mathrm{E}-11$ & 5 & 50582954 & 50974050 & CTD-233503.3 \\
\hline rs4075651 & 5 & 107878588 & $8,80016 \mathrm{E}-09$ & 6 & $1,08 \mathrm{E}+08$ & $1,08 \mathrm{E}+08$ & $R P 11-120 B 7.1$ \\
\hline rs10456089 & 6 & 11959836 & 2,76627E-09 & 7 & 11959836 & 12056771 & $R P 11-456 H 18.1$ \\
\hline rs4839780 & 6 & 100909398 & $1,27664 \mathrm{E}-08$ & 8 & $1,01 E+08$ & $1,01 E+08$ & SIM1 \\
\hline rs34979551 & 6 & 100848871 & $1,37312 \mathrm{E}-08$ & 8 & $1,01 E+08$ & $1,01 E+08$ & SIM1 \\
\hline
\end{tabular}




\begin{tabular}{|l|r|r|r|r|r|l|l|}
\hline rs6976111 & 7 & 117495667 & $4,62794 \mathrm{E}-10$ & 9 & $1,17 \mathrm{E}+08$ & $1,18 \mathrm{E}+08$ & CTTNBP2 \\
\hline rs3793577 & 9 & 23737627 & $4,68151 \mathrm{E}-10$ & 10 & 23720380 & 23741776 & ELAVL2 \\
\hline rs10761244 & 9 & 96387592 & $8,36369 \mathrm{E}-09$ & 11 & 96384524 & 96460883 & PHF2 \\
\hline rs71507562 & 9 & 121640304 & $1,79161 \mathrm{E}-08$ & 12 & $1,22 \mathrm{E}+08$ & $1,22 \mathrm{E}+08$ & TUBB4BP6 \\
\hline rs34588274 & 11 & 13269946 & $1,05085 \mathrm{E}-13$ & 13 & 13268067 & 13350131 & ARNTL \\
\hline rs527528 & 11 & 57433327 & $4,11682 \mathrm{E}-10$ & 14 & 57404779 & 57756568 & ZDHHC5 \\
\hline rs4245154 & 11 & 113388674 & $7,36147 \mathrm{E}-09$ & 15 & $1,13 \mathrm{E}+08$ & $1,13 \mathrm{E}+08$ & DRD2 \\
\hline rs3742021 & 12 & 109883117 & $7,61756 \mathrm{E}-09$ & 16 & $1,1 \mathrm{E}+08$ & $1,1 \mathrm{E}+08$ & MYO1H \\
\hline rs3784060 & 14 & 72114138 & $1,83262 \mathrm{E}-08$ & 17 & 71757418 & 72162901 & SIPA1L1 \\
\hline rs2216270 & 18 & 63656060 & $1,30878 \mathrm{E}-08$ & 18 & 63650084 & 63668364 & $R P 11-389 J 22.3$ \\
\hline
\end{tabular}

Table 1: Table 1 shows the location, the significance value and the nearest gene for the 19 lead SNPs of the 18 genomic loci that pass the threshold for genome-wide significance $(p<5 * 10-8)$ in the GWAS of the sociability measure in the UK Biobank sample. chr: chromosome, pos: position.

Genetic correlation

The genetic correlation between sociability and SCZ (0.1532, se=0.0156, $p=9.8 * 10-23)$, MDD (0.6761, se $=0.0201, p=6.5 * 10-248)$ and ASDs (0.2694, se=0.0245, $p=4.5 * 10-28)$ was significantly positive. No significant genetic correlation was found between sociability and BP or AD. Sociability was positively genetically correlated with Loneliness $(0.4525, \mathrm{se}=0.081, \mathrm{p}=2.4 * 10-8)$ and Social Anxiety $(0.4755$, se $=0.154, p=0.002)$, see Table 2 . 


\begin{tabular}{|c|c|c|c|c|}
\hline & $\underline{\operatorname{Rg}(\text { se) }}$ & p-value & sample size & $\underline{\text { PMID }}$ \\
\hline So-BIP & $\begin{array}{l}0.0142 \\
(0.019)\end{array}$ & 0.4549 & 20,352 cases, 31,358 controls & 31043756 \\
\hline So-SCZ & $\begin{array}{l}0.1532 \\
(0.0156)\end{array}$ & $9.81^{\mathrm{e}}-23$ & $\begin{array}{l}34,241 \text { cases, } 45,604 \text { controls, } \\
1235 \text { trios }\end{array}$ & 25056061 \\
\hline So-MDD & $\begin{array}{l}0.6761 \\
(0.0201)\end{array}$ & 6.57 e-248 & 59,851 cases, 113,154 controls & 29700475 \\
\hline So-ASD & $\begin{array}{l}0.2694 \\
(0.0245)\end{array}$ & 4.5 e-28 & 18,381 cases, 27,969 controls & 30804558 \\
\hline So-AD & $\begin{array}{l}0.0392 \\
(0.0277)\end{array}$ & 0.5747 & 17,008 cases, 37,154 controls & 24162737 \\
\hline $\begin{array}{l}\text { So- } \\
\text { Loneliness }\end{array}$ & $\begin{array}{l}0.4525 \\
(0.0811)\end{array}$ & $2.4^{\mathrm{e}}-8$ & 7556 & 27629369 \\
\hline So-SoAnx & $\begin{array}{l}0.4755 \\
(0.154)\end{array}$ & 0.002 & 11,268 & 28224735 \\
\hline
\end{tabular}

Table 2: Genetic correlation between the sociability measure in UKBB (So) and case control datasets of Bipolar Disorder (BIP), Schizophrenia (SCZ), Major Depressive Disorder (MDD), Autism Spectrum Disorders (ASD), Alzheimer's disease (AD), and population-based cohorts on Loneliness and Social Anxiety(SoAnx). Significant genetic correlations are indicated in bold. 


\section{DISCUSSION}

In the current study we show that sociability, as constructed from 4 sociability-related self-report questions in the UKBB, was increased in individuals with ASD, BP, (probable) MDD and SCZ, but not in individuals with AD. Performing a genome-wide association study on a sociability score, we report 604 genome-wide significant SNPs, coming from 18 independent loci. We were able to show that sociability in the general population is genetically correlated with SCZ, MDD and ASDs, but not with BP and AD.

By constructing an aggregated measure of sociability in a large population-based cohort we were able to show that difficulties with sociability are indeed a common feature in multiple disorders. With the UK Biobank cohort collecting data on 'probable MDD' and the occurrence of 'Recurrent Depressive Episodes' and the diagnoses of ASD, BP and SCZ we could clearly show that our construct was increased in these individuals, compared to the individuals who did not report such incidents, and could therefore be considered a cross-disorder feature. Although difficulties with sociability have also been linked to the neurological disorder $A D$, we did not find a phenotypic link between our sociability construct and AD, even though the AD measure in the UKBB has been reported to capture $A D$ risk in previous genetic studies (Jansen et al., 2019; Marioni et al., 2018). Not finding a phenotypic association between sociability and $A D$ is potentially in line with previous work that highlight that difficulties in sociability might not be an early sign of $A D$, but rather a risk factor for AD. Where the risk of developing $A D$ was found to be increased in individuals who reported to feel lonely, as well as with lower levels of cognition and more rapid cognitive decline, post-mortem analysis on the individuals that ceased away showed that loneliness scores were unrelated to summary measures of AD pathology, like nerve plaques and tangles, or tissue damaged by lack of blood flow (Wilson et al., 2007). However, a recent study using an in vivo method, measuring an aggregated measure of cortical amyloid burden in cognitive normal elderly individuals was able to show a link between selfreported loneliness and cortical amyloid burden, a putative biomarker of $A D$, indicating loneliness to be a symptom relevant to preclinical AD (Donovan et al., 2016). Next to loneliness, the social aspect of our construct has been investigated as well in patients with $A D$, and maintaining or developing a close friendship network has indeed been shown to be beneficial for cognition, however this social aspect was not associated to psychopathology (as measured by 12 neuropsychiatric symptoms, like disinhibition, sleep and depression/dysphoria)(Balouch, Rifaat, Chen, \& Tabet, 2019). However, we do need to highlight that with AD being an age-related disorder, the phenotype we used in the current study is noisy, as the individuals contributing to the UKBB might not have reached the age to develop AD.

After relating our construct to multiple disorders phenotypically, we were interested to measure if our construct was influenced by common genetic variants. Indeed we found a SNP-based heritability of $6 \%$, which is in line with SNP-based heritabilities that have been reported before for related constructs (4.2\%-16\% for loneliness(Day et al., 2018; Gao et al., 2017) , 3.4\%-5\% for social interactions (Day et al., 2018), 12\% for social anxiety (Stein et al., 2017)). By performing a GWAS in the large scale UK Biobank project, we had the statistical power to detect 18 robust genome-wide significant loci, coming from 19 lead SNPs. The strongest association signal was observed on chromosome 11p15 ( $r$ 34588274, p=1.05E-13). This loci includes the ARNTL gene, which is a circadian clock gene (Rudic et al., 2004). Circadian disruptions, like delayed sleep, reduced sleep efficiency, difficulties falling asleep, early awakenings and higher levels of day-time sleepiness are common among SCZ, BP , MDD and neurodegenerative diseases (Landgraf, McCarthy, \& Welsh, 2014; Tsuno, Besset, \& Ritchie, 2005; Wulff, Gatti, Wettstein, \& Foster, 2010). Indeed genetic variants within core clock genes, including ARTNL have been linked to psychiatric disorders and AD (Charrier, Olliac, Roubertoux, \& Tordjman, 2017; Chen, Peng, Huang, Hu, \& Zhang, 2015; Gonzalez et al., 2015; Kim et al., 2015). Interestingly the lead SNP in this region, $r s 34588274$, has previously been linked to neuroticism, well-being spectrum (life satisfaction, positive affect, neuroticism, and depressive symptoms, collectively referred to as the well-being spectrum), positive affect and BMI (GWAS catalog, https://www.ebi.ac.uk/gwas/(Baselmans et al., 2019; Nagel et al., 2018)), indicating that our 
construct indeed seems to capture aspects related to sociability. This is also supported by the significant positive genetic correlations of our GWAS to loneliness (Gao et al., 2017) and social anxiety (Stein et al., 2017).

Also the genome-wide significant loci on chromosome 11q ( $r s 4245154, p=7.36 \mathrm{E}-09$ ) includes a wellstudied candidate gene for multiple disorders, including SCZ, being DRD2. DRD2, dopamine receptor 2 , encodes the D2 subtype of the dopamine receptor. This is of particular interest because DRD2 is one of the few examples where GWAS (of SCZ), after increasing sample sizes to the thousands, was able to find genome-wide significance for a previously 'expected' candidate gene (Ripke et al., 2014). Since our top SNP was also significant in the GWAS of MDD, as well as the GWAS of SCZ (D. Howard et al., 2019; Ripke et al., 2014), this hints that our sociability construct is tapping onto genetically shared mechanisms between multiple disorders.

Another interesting genome-wide significant loci is the loci on chromosome 9p21 (rs3793577, $\mathrm{p}=4.68 \mathrm{E}-10$ ), which includes the $E L A V L 2$ gene. The protein encoded by this gene is a neural-specific RNA-binding protein, that has also been reported in the latest MDD GWAS (D. Howard et al., 2019).

This is the first study to investigate the genetics of sociability as an added construct, including loneliness, social relationships, social embarrassment and social activities. Although other studies have investigated the influence of common genetic variants on single parts of this construct, like loneliness (Gao et al., 2017), or using a multi-trait (MTAG) design including loneliness, frequency of social interactions, and ability to confide in someone in the same analysis (Day et al., 2018), we went for an added construct. Our construct clearly showed a phenotypic link to multiple disorders, thereby verifying that we are investigating a clinically relevant construct. We did not perform a multi-trait design because our data did not satisfy the assumptions required for performing MTAG analyses, including the genetic correlations between the single questions being higher than 0.7 and a high value of the mean $\chi^{2}$-statistic of our trait (Turley et al., 2018).

By performing genetic correlation analyses between our GWAS of sociability and the latest publicly available disorder GWAS summary statistics we were able to show that sociability genetically correlate with SCZ, ASD, and MDD, but not with BP and AD. The finding that the neurological disorder $A D$ does not genetically link to the same construct as psychiatric disorders is in line with previous findings, showing that genetic sharing was high between psychiatric disorders (including significant genetic correlations between ASD \& SCZ, SCZ \& MDD, SCZ \& BP and MDD \& BP), but low between AD and psychiatric disorders (ASD, SCZ, MDD and BP all non-significantly correlated with AD) (Anttila et al., 2018). However, the (genetic) relationship between SCZ and BP is well known, making the (genetic) distinction of BP potentially less expected. Although social impairment characterize BP, even during remitted phases, the link between social relationships and BP seems to be relating to depressive symptoms, and not to manic episodes (Goldstein, Miklowitz, \& Mullen, 2006). Indeed patients with BP fluctuate between depressive states and manic states, where in the manic states they have periods where they have increased levels of energy and are very sociable. Opposite to the depressive period, the manic periods might be characterized by an increase in social visits, feeling less socially embarrassed and having the energy to visit public social places, the four aspects covered in our sociability construct. This distinction might be in line with our results showing a very high genetic correlation to depression (clinical MDD), that might be diluted in a clinical sample that includes both depressive and manic episodes.

This study should be viewed in the light of some strengths and limitations. A major strength of the current study is the large sample size, providing us the power to detect prosperous single-variant genetic associations as also shown by our robustness analyses. Another main strength is the combined phenotype used, which is capturing a sociability construct shared between disorders. A limitation of the current study is the modest SNP-based heritability found for our sociability measure, 
bioRxiv preprint doi: https://doi.org/101101/781195. this version posted October 23, 2019. The copyriaht holder for this preprint (which was not certified by peer review) is the author/funder, who has granted bioRxiv a license to display the preprint in perpetuity. It is made available under aCC-BY-NC 4.0 International license.

indicating we are only touching on part of the heritability of the complex multifactorial disorders showing difficulties with sociability as an overlapping symptom.

To conclude, our data shows there is a significant genetic component to the variation in population levels of sociability. The genetic contribution to sociability is relevant to the psychiatric disorders ASD, MDD and SCZ, but not to BP and the neurological disorder AD. 


\section{CONFLICTS OF INTEREST}

Dr. Arango. has been a consultant to or has received honoraria or grants from Acadia, Angelini, Gedeon Richter, Janssen Cilag, Lundbeck, Otsuka, Roche, Sage, Servier, Shire, Schering Plough, Sumitomo Dainippon Pharma, Sunovion and Takeda. Barbara Franke has received educational speaking fees from Shire and Medice.

\section{ACKNOWLEDGEMENTS}

The PRISM project (www.prism-project.eu) leading to this application has received funding from the Innovative Medicines Initiative 2 Joint Undertaking under grant agreement No 115916. This Joint Undertaking receives support from the European Union's Horizon 2020 research and innovation programme and EFPIA. This publication reflects only the authors' views neither IMI JU nor EFPIA nor the European Commission are liable for any use that may be made of the information contained therein. Support by the EU H2020 Program under the Innovative Medicines Initiative 2 Joint Undertaking with grant agreement 777394 (AIMS-2-TRIALS), the Spanish Ministry of Science, Innovation and Universities, Instituto de Salud Carlos III (PI14/00397, PI14/02103, PIE16/00055, $\mathrm{PI} 17 / 00819, \mathrm{PI} 17 / 00481)$, co-financed by ERDF Funds from the European Commission, "A way of making Europe", CIBERSAM, Madrid Regional Government (B2017/BMD-3740 AGES-CM-2), EU Structural Funds, EU Seventh Framework Program under grant agreement FP7-HEALTH-2013-2.2.1-2603196 (Project PSYSCAN), Fundación Familia Alonso, Fundación Alicia Koplowitz. 


\section{SUPPLEMENTARY DATA}

Supplement 1: Scoring of the questions

Total score for sociability=sum of scores on questions 1-4; range: $0-4$. The sociability score was scored in such a way that a higher score indicated more difficulties with sociability.

\section{QUESTIONS and SCORING}

\section{Frequency of friend / family visits (Data-Field 1031)}

How often do you visit friends or family or have them visit you? (Hint: If this varies, please give an average of how often you visit or have had visits in the last year. Include meeting with friends or family in environments outside of the home such as in the park, at a sports field, at a restaurant or pub.)

\begin{tabular}{|l|l|}
\hline ANSWER & SCORE \\
\hline 1. Almost daily & 0 \\
\hline 2. 2-4 times a week & 0.2 \\
\hline 3. About once a week & 0.4 \\
\hline 4. About once a month & 0.6 \\
\hline 5. Once every few months & 0.8 \\
\hline 6. Never or almost never & 1 \\
\hline 7. No friends/family outside household & - exclude \\
\hline 8. Do not know & - exclude \\
\hline 9. Prefer not to answer & - exclude \\
\hline
\end{tabular}

\section{Leisure / social activities (Data-Field 6160)}

Which of the following do you attend once a week or more often? (You can select more than one) (Hint: If this varies, please think about activities in the last year.)

\begin{tabular}{|l|l|}
\hline ANSWER & SCORE \\
\hline 1. Sports club or gym & \\
\hline
\end{tabular}


bioRxiv preprint doi: https://doi org/10 1101/781195: this version posted October 23,2019 . The copyriaht holder for this preprint (which was not certified by peer review) is the author/funder, who has granted bioRxiv a license to display the preprint in perpetuity. It is made available under aCC-BY-NC 4.0 International license.

\begin{tabular}{|l|l|}
\hline 2. Pub or social club & \multirow{2}{*}{ At least one of these answers: 0} \\
\cline { 1 - 1 } 3. Religious group & \\
\cline { 1 - 2 } 4. Adult education class & \\
\cline { 1 - 1 } 5. Other group activity & \\
\hline 6. None of the above & 1 \\
\hline 7. Prefer not to answer & - exclude \\
\hline
\end{tabular}

3. Worry after social embarrassment (Data-Field 2000) Do you worry too long after an embarrassing experience?

\begin{tabular}{|l|l|}
\hline ANSWER & SCORE \\
\hline 1. Yes & 1 \\
\hline 2. No & 0 \\
\hline 3. Do not know & - exclude \\
\hline 4. Prefer not to answer & - exclude \\
\hline
\end{tabular}

4. Loneliness (Data-Field 2020)

Do you often feel lonely?

\begin{tabular}{|l|l|}
\hline ANSWER & SCORE \\
\hline 1. Yes & 1 \\
\hline 2. No & 0 \\
\hline 3. Do not know & - exclude \\
\hline 4. Prefer not to answer & - exclude \\
\hline
\end{tabular}


bioRxiv preprint doi: https://doi.org/10.1101/781195; this version posted October 23, 2019. The copyright holder for this preprint (which was not certified by peer review) is the author/funder, who has granted bioRxiv a license to display the preprint in perpetuity. It is made available under aCC-BY-NC 4.0 International license.

Supplement 2: Distribution of total sociability score

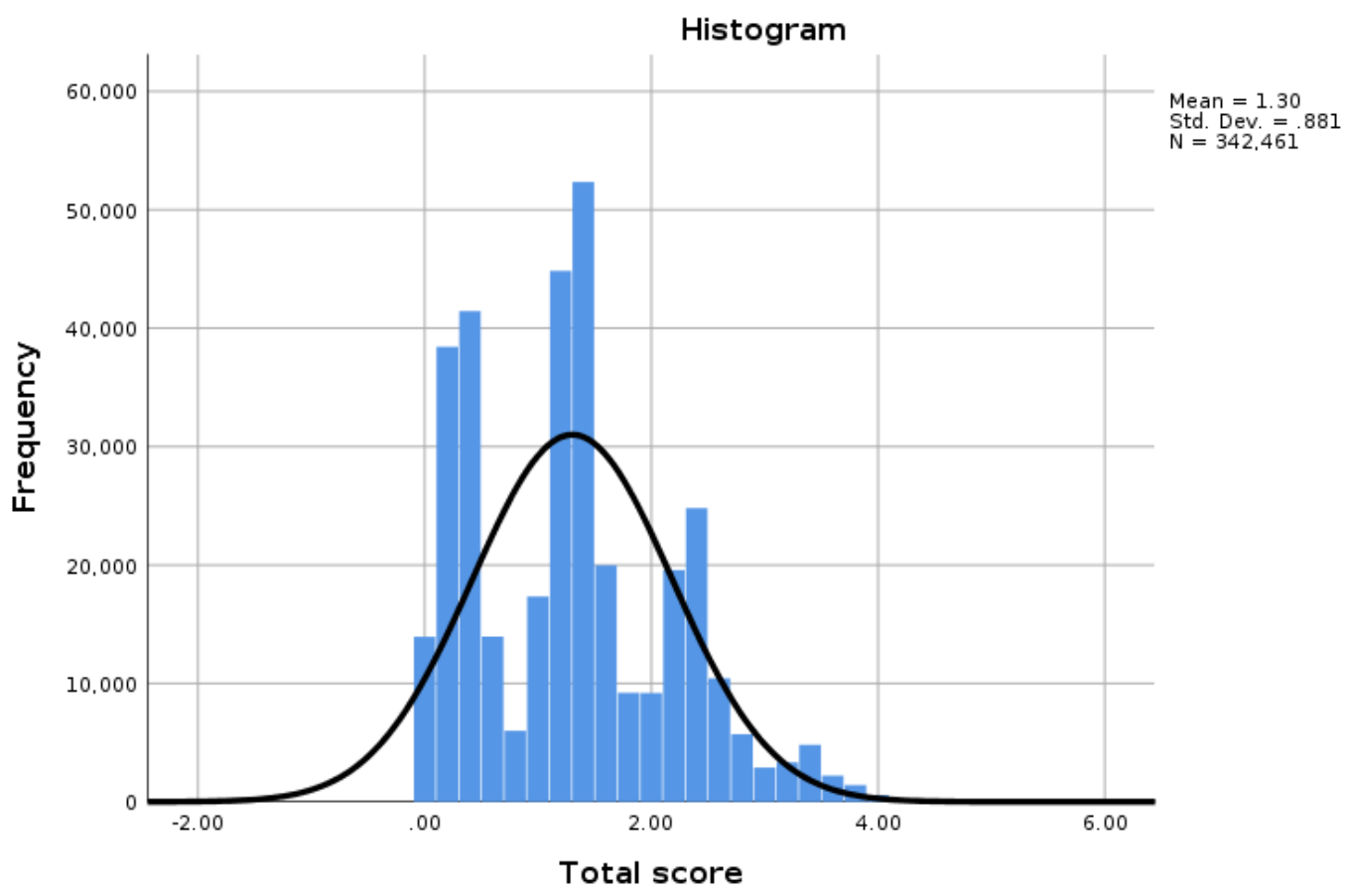




\section{REFERENCES}

Addington, J., \& Addington, D. (2008). Social and cognitive functioning in psychosis. Schizophrenia Research, 99(1-3), 176-181. Retrieved from https://www.ncbi.nlm.nih.gov/pubmed/17681756. doi:10.1016/j.schres.2007.07.004

Addington, J., Penn, D., Woods, S. W., Addington, D., \& Perkins, D. O. (2008). Social functioning in individuals at clinical high risk for psychosis. Schizophrenia Research, 99(1-3), 119-124.

Retrieved from https://www.ncbi.nlm.nih.gov/pubmed/18023329. doi:10.1016/j.schres.2007.10.001

Anttila, V., Bulik-Sullivan, B., Finucane, H. K., Walters, R. K., Bras, J., Duncan, L., . . Consortium, B. (2018). Analysis of shared heritability in common disorders of the brain. Science, 360(6395), 1313-+. Retrieved from <Go to ISI>://WOS:000436040600034. doi:ARTN eaap875710.1126/science.aap8757

Balouch, S., Rifaat, E., Chen, H. L., \& Tabet, N. (2019). Social networks and loneliness in people with Alzheimer's dementia. Int J Geriatr Psychiatry, 34(5), 666-673. Retrieved from https://www.ncbi.nlm.nih.gov/pubmed/30706526. doi:10.1002/gps.5065

Baselmans, B. M. L., van de Weijer, M. P., Abdellaoui, A., Vink, J. M., Hottenga, J. J., Willemsen, G., ... Bartels, M. (2019). A Genetic Investigation of the Well-Being Spectrum. Behavior Genetics, 49(3), 286-297. Retrieved from https://www.ncbi.nlm.nih.gov/pubmed/30810878. doi:10.1007/s10519-019-09951-0

Bellack, A. S., Schooler, N. R., Marder, S. R., Kane, J. M., Brown, C. H., \& Yang, Y. (2004). Do clozapine and risperidone affect Social Competence and problem solving? American Journal of Psychiatry, 161(2), 364-367. Retrieved from <Go to ISI>://WOS:000221275900026. doi:DOI 10.1176/appi.ajp.161.2.364

Boomsma, D. I., Cacioppo, J. T., Slagboom, P. E., \& Posthuma, D. (2006). Genetic linkage and association analysis for loneliness in Dutch twin and sibling pairs points to a region on chromosome 12q23-24. Behavior Genetics, 36(1), 137-146. Retrieved from <Go to $|S|>: / / W O S: 000236832300015$. doi:10.1007/s10519-005-9005-z

Boomsma, D. I., Willemsen, G., Dolan, C. V., Hawkley, L. C., \& Cacioppo, J. T. (2005). Genetic and environmental contributions to loneliness in adults: The Netherlands twin register study. Behavior Genetics, 35(6), 745-752. Retrieved from <Go to ISI>://WOS:000233391600005. doi:10.1007/s10519-005-6040-8

Bora, E., \& Berk, M. (2016). Theory of mind in major depressive disorder: A meta-analysis. J Affect Disord, 191, 49-55. Retrieved from https://www.ncbi.nlm.nih.gov/pubmed/26655114. doi:10.1016/j.jad.2015.11.023

Bulik-Sullivan, B., Finucane, H. K., Anttila, V., Gusev, A., Day, F. R., Loh, P. R., . . Neale, B. M. (2015). An atlas of genetic correlations across human diseases and traits. Nature Genetics, 47(11), 1236-1241. Retrieved from https://www.ncbi.nlm.nih.gov/pubmed/26414676. doi:10.1038/ng.3406

Bulik-Sullivan, B. K., Loh, P. R., Finucane, H. K., Ripke, S., Yang, J., Schizophrenia Working Group of the Psychiatric Genomics, C., ... Neale, B. M. (2015). LD Score regression distinguishes confounding from polygenicity in genome-wide association studies. Nature Genetics, 47(3), 291-295. Retrieved from https://www.ncbi.nlm.nih.gov/pubmed/25642630. doi:10.1038/ng.3211

Bycroft, C., Freeman, C., Petkova, D., Band, G., Elliott, L. T., Sharp, K., ... Marchini, J. (2018). The UK Biobank resource with deep phenotyping and genomic data. Nature, 562(7726), 203-+. Retrieved from <Go to ISI>://WOS:000446920400040. doi:10.1038/s41586-018-0579-z

Cacioppo, S., Grippo, A. J., London, S., Goossens, L., \& Cacioppo, J. T. (2015). Loneliness: Clinical Import and Interventions. Perspectives on Psychological Science, 10(2), 238-249. Retrieved from <Go to ISI >://WOS:000351242300009. doi:10.1177/1745691615570616 
Charrier, A., Olliac, B., Roubertoux, P., \& Tordjman, S. (2017). Clock Genes and Altered Sleep-Wake Rhythms: Their Role in the Development of Psychiatric Disorders. Int J Mol Sci, 18(5).

Retrieved from https://www.ncbi.nlm.nih.gov/pubmed/28468274. doi:10.3390/ijms18050938

Chen, Q., Peng, X. D., Huang, C. Q., Hu, X. Y., \& Zhang, X. M. (2015). Association between ARNTL (BMAL1) rs2278749 polymorphism $\mathrm{T}>\mathrm{C}$ and susceptibility to Alzheimer disease in a Chinese population. Genetics and Molecular Research, 14(4), 18515-18522. Retrieved from https://www.ncbi.nlm.nih.gov/pubmed/26782499. doi:10.4238/2015.December.23.39

Chisholm, K., Lin, A., Abu-Akel, A., \& Wood, S. J. (2015). The association between autism and schizophrenia spectrum disorders: A review of eight alternate models of co-occurrence. Neurosci Biobehav Rev, 55, 173-183. Retrieved from https://www.ncbi.nlm.nih.gov/pubmed/25956249. doi:10.1016/j.neubiorev.2015.04.012

Cross, S. P. M., Scott, J., \& Hickie, I. B. (2017). Predicting early transition from sub-syndromal presentations to major mental disorders. Bjpsych Open, 3(5), 223-227. Retrieved from $<\mathrm{Go}$ to $|S|>: / /$ WOS:000418507300003. doi:10.1192/bjpo.bp.117.004721

Day, F. R., Ong, K. K., \& Perry, J. R. B. (2018). Elucidating the genetic basis of social interaction and isolation. Nature Communications, 9. Retrieved from <Go to ISI>://WOS:000437101200001. doi:ARTN 245710.1038/s41467-018-04930-1

Dickerson, B. C. (2015). Dysfunction of social cognition and behavior. Continuum (Minneap Minn), 21(3 Behavioral Neurology and Neuropsychiatry), 660-677. Retrieved from https://www.ncbi.nlm.nih.gov/pubmed/26039847. doi:10.1212/01.CON.0000466659.05156.1d

Distel, M. A., Rebollo-Mesa, I., Abdellaoui, A., Derom, C., Willemsen, G., Cacioppo, J. T., \& Boomsma, D. I. (2010). Familial Resemblance for Loneliness. Behavior Genetics, 40(4), 480-494.

Retrieved from $<$ Go to ISI $>$ ://WOS:000278897500006. doi:10.1007/s10519-010-9341-5

Donovan, N. J., Okereke, O. I., Vannini, P., Amariglio, R. E., Rentz, D. M., Marshall, G. A., . . Sperling, R. A. (2016). Association of Higher Cortical Amyloid Burden With Loneliness in Cognitively Normal Older Adults. Jama Psychiatry, 73(12), 1230-1237. Retrieved from https://www.ncbi.nlm.nih.gov/pubmed/27806159. doi:10.1001/jamapsychiatry.2016.2657

Filizer, A. T., Cerit, C., Tuzun, B., \& Aker, A. T. (2016). Social Aspect of Functioning Deteriorates More Than Individual Aspect in Patients with Remitted Bipolar Disorder. Noropsikiyatri ArsiviArchives of Neuropsychiatry, 53(2), 158-162. Retrieved from <Go to $|S|>: / / W O S: 000379331000012$. doi:10.5152/npa.2015.10106

Finucane, H. K., Bulik-Sullivan, B., Gusev, A., Trynka, G., Reshef, Y., Loh, P. R., . . Consortium, R. (2015). Partitioning heritability by functional annotation using genome-wide association summary statistics. Nature Genetics, $47(11), 1228-+$. Retrieved from $<$ Go to $|S|>: / / W O S: 000363988200005$. doi:10.1038/ng.3404

Galderisi, S., Mucci, A., Buchanan, R. W., \& Arango, C. (2018). Negative symptoms of schizophrenia: new developments and unanswered research questions. Lancet Psychiatry, 5(8), 664-677. Retrieved from https://www.ncbi.nlm.nih.gov/pubmed/29602739. doi:10.1016/S22150366(18)30050-6

Gao, J. J., Davis, L. K., Hart, A. B., Sanchez-Roige, S., Han, L. D., Cacioppo, J. T., \& Palmer, A. A. (2017). Genome-Wide Association Study of Loneliness Demonstrates a Role for Common Variation. Neuropsychopharmacology, 42(4), 811-821. Retrieved from $<$ Go to |S|>://WOS:000393725600004. doi:10.1038/npp.2016.197

Gatz, M., Reynolds, C. A., Fratiglioni, L., Johansson, B., Mortimer, J. A., Berg, S., . . Pedersen, N. L. (2006). Role of genes and environments for explaining Alzheimer disease. Archives of General Psychiatry, 63(2), 168-174. Retrieved from <Go to ISI ://WOS:000235150900007. doi:DOI 10.1001/archpsyc.63.2.168 
Goldstein, T. R., Miklowitz, D. J., \& Mullen, K. L. (2006). Social skills knowledge and performance among adolescents with bipolar disorder. Bipolar Disord, 8(4), 350-361. Retrieved from https://www.ncbi.nlm.nih.gov/pubmed/16879136. doi:10.1111/j.1399-5618.2006.00321.x

Gonzalez, R., Gonzalez, S., Villa, E., Ramirez, M., Zavala, J., Armas, R., ... Escamilla, M. (2015). Identification of circadian gene variants in bipolar disorder in Latino populations. J Affect Disord, 186, 367-375. Retrieved from https://www.ncbi.nlm.nih.gov/pubmed/26283580. doi:10.1016/j.jad.2015.07.014

Green, M. F., Horan, W. P., \& Lee, J. (2015). Social cognition in schizophrenia. Nature Reviews Neuroscience, 16(10), 620-631. Retrieved from <Go to ISI>://WOS:000361691900009. doi:10.1038/nrn4005

Grove, J., Ripke, S., Als, T. D., Mattheisen, M., Walters, R. K., Won, H., .. Team, a. R. (2019). Identification of common genetic risk variants for autism spectrum disorder. Nature Genetics, 51(3), 431-+. Retrieved from <Go to ISI>://WOS:000459947200012. doi:10.1038/s41588-0190344-8

Hilker, R., Helenius, D., Fagerlund, B., Skytthe, A., Christensen, K., Werge, T. M., . . Glenthoj, B. (2018). Heritability of Schizophrenia and Schizophrenia Spectrum Based on the Nationwide Danish Twin Register. Biological Psychiatry, 83(6), 492-498. Retrieved from <Go to |S|>://WOS:000424667200007. doi:10.1016/j.biopsych.2017.08.017

Holt-Lunstad, J., Smith, T. B., Baker, M., Harris, T., \& Stephenson, D. (2015). Loneliness and Social Isolation as Risk Factors for Mortality: A Meta-Analytic Review. Perspectives on Psychological Science, 10(2), 227-237. Retrieved from <Go to $|S|>: / /$ WOS:000351242300008. doi:10.1177/1745691614568352

Howard, D., Clarke, T., Adams, M., Hafferty, J., Wigmore, E., Zeng, Y. N., . . Consortium, P. G. (2019). The Identification of Heterogeneous Genetic Subgroups for Major Depressive Disorder. European Neuropsychopharmacology, 29, S846-S846. Retrieved from <Go to $|S|>: / / W O S: 000462156400245$. doi:10.1016/j.euroneuro.2017.08.116

Howard, D. M., Adams, M. J., Shirali, M., Clarke, T. K., Marioni, R. E., Davies, G., . . McIntosh, A. M. (2018). Genome-wide association study of depression phenotypes in UK Biobank identifies variants in excitatory synaptic pathways. Nature Communications, 9(1), 1470. Retrieved from https://www.ncbi.nlm.nih.gov/pubmed/29662059. doi:10.1038/s41467-018-03819-3

Jansen, I. E., Savage, J. E., Watanabe, K., Bryois, J., Williams, D. M., Steinberg, S., . . Posthuma, D. (2019). Genome-wide meta-analysis identifies new loci and functional pathways influencing Alzheimer's disease risk. Nature Genetics, 51(3), 404-+. Retrieved from <Go to |S|>://WOS:000459947200010. doi:10.1038/s41588-018-0311-9

Johansson, V., Kuja-Halkola, R., Cannon, T. D., Hultman, C. M., \& Hedman, A. M. (2019). A populationbased heritability estimate of bipolar disorder - In a Swedish twin sample. Psychiatry Research, 278, 180-187. Retrieved from <Go to ISI ://WOS:000477689600024. doi:10.1016/j.psychres.2019.06.010

Kas, M. J., Penninx, B., Sommer, B., Serretti, A., Arango, C., \& Marston, H. (2019). A quantitative approach to neuropsychiatry: The why and the how. Neurosci Biobehav Rev, 97, 3-9. Retrieved from https://www.ncbi.nlm.nih.gov/pubmed/29246661. doi:10.1016/j.neubiorev.2017.12.008

Kim, H. I., Lee, H. J., Cho, C. H., Kang, S. G., Yoon, H. K., Park, Y. M., . . Kim, L. (2015). Association of CLOCK, ARNTL, and NPAS2 gene polymorphisms and seasonal variations in mood and behavior. Chronobiol Int, 32(6), 785-791. Retrieved from https://www.ncbi.nlm.nih.gov/pubmed/26134245. doi:10.3109/07420528.2015.1049613

Kitamura, T., \& Suga, R. (1991). Depressive and Negative Symptoms in Major Psychiatric-Disorders. Comprehensive Psychiatry, 32(1), 88-94. Retrieved from $<$ Go to $|S|>: / / W O S: A 1991 E Q 56100011$. doi:Doi 10.1016/0010-440x(91)90074-M

Kupferberg, A., Bicks, L., \& Hasler, G. (2016). Social functioning in major depressive disorder. Neuroscience and Biobehavioral Reviews, 69, 313-332. Retrieved from <Go to |S|>://WOS:000385323500022. doi:10.1016/j.neubiorev.2016.07.002 
Lambert, J. C., Ibrahim-Verbaas, C. A., Harold, D., Naj, A. C., Sims, R., Bellenguez, C., . . Charge. (2013). Meta-analysis of 74,046 individuals identifies 11 new susceptibility loci for Alzheimer's disease. Nature Genetics, 45(12), 1452-U1206. Retrieved from <Go to |S|>://WOS:000327715800010. doi:10.1038/ng.2802

Landgraf, D., McCarthy, M. J., \& Welsh, D. K. (2014). Circadian clock and stress interactions in the molecular biology of psychiatric disorders. Curr Psychiatry Rep, 16(10), 483. Retrieved from https://www.ncbi.nlm.nih.gov/pubmed/25135782. doi:10.1007/s11920-014-0483-7

Lee, H. B., \& Lyketsos, C. G. (2003). Depression in Alzheimer's disease: heterogeneity and related issues. Biol Psychiatry, 54(3), 353-362. Retrieved from https://www.ncbi.nlm.nih.gov/pubmed/12893110. doi:10.1016/s0006-3223(03)00543-2

Lord, C., Elsabbagh, M., Baird, G., \& Veenstra-Vanderweele, J. (2018). Autism spectrum disorder. Lancet, 392(10146), 508-520. Retrieved from https://www.ncbi.nlm.nih.gov/pubmed/30078460. doi:10.1016/S0140-6736(18)31129-2

Marioni, R. E., Harris, S. E., Zhang, Q., McRae, A. F., Hagenaars, S. P., Hill, W. D., . . Visscher, P. M. (2018). GWAS on family history of Alzheimer's disease. Transl Psychiatry, 8(1), 99. Retrieved from https://www.ncbi.nlm.nih.gov/pubmed/29777097. doi:10.1038/s41398-018-0150-6

Nagel, M., Jansen, P. R., Stringer, S., Watanabe, K., de Leeuw, C. A., Bryois, J., . . Posthuma, D. (2018). Meta-analysis of genome-wide association studies for neuroticism in 449,484 individuals identifies novel genetic loci and pathways. Nature Genetics, 50(7), 920-927. Retrieved from https://www.ncbi.nlm.nih.gov/pubmed/29942085. doi:10.1038/s41588-0180151-7

Nelis, S. M., Clare, L., Martyr, A., Markova, I., Roth, I., Woods, R. T., ... Morris, R. G. (2011). Awareness of social and emotional functioning in people with early-stage dementia and implications for carers. Aging \& Mental Health, 15(8), 961-969. Retrieved from <Go to $|S|>: / / W O S: 000299482800005$. doi:10.1080/13607863.2011.575350

Ordonana, J. R., Bartels, M., Boomsma, D. I., Cella, D., Mosing, M., Oliveira, J. R., . . Consortium, G. (2013). Biological pathways and genetic mechanisms involved in social functioning. Quality of Life Research, 22(6), 1189-1200. Retrieved from <Go to ISI>://WOS:000322735700003. doi:10.1007/s11136-012-0277-5

Porcelli, S., Van Der Wee, N., van der Werff, S., Aghajani, M., Glennon, J. C., van Heukelum, S., . . . Serretti, A. (2019). Social brain, social dysfunction and social withdrawal. Neurosci Biobehav Rev, 97, 10-33. Retrieved from https://www.ncbi.nlm.nih.gov/pubmed/30244163. doi:10.1016/j.neubiorev.2018.09.012

Rai, D., Heuvelman, H., Dalman, C., Culpin, I., Lundberg, M., Carpenter, P., \& Magnusson, C. (2018). Association Between Autism Spectrum Disorders With or Without Intellectual Disability and Depression in Young Adulthood. JAMA Netw Open, 1(4), e181465. Retrieved from https://www.ncbi.nlm.nih.gov/pubmed/30646131. doi:10.1001/jamanetworkopen.2018.1465

Reeb-Sutherland, B. C., Levitt, P., \& Fox, N. A. (2012). The Predictive Nature of Individual Differences in Early Associative Learning and Emerging Social Behavior. Plos One, $7(1)$. Retrieved from $<$ Go to ISI>://WOS:000301570600050. doi:ARTN e3051110.1371/journal.pone.0030511

Reichman, W. E., \& Negron, A. (2001). Negative symptoms in the elderly patient with dementia. International Journal of Geriatric Psychiatry, 16, S7-S11. Retrieved from <Go to ISI :://WOS:000173132000003. doi:Doi 10.1002/1099-1166(200112)16:1+<::AidGps566>3.0.Co;2-S

Ripke, S., Neale, B. M., Corvin, A., Walters, J. T. R., Farh, K. H., Holmans, P. A., . . Consor, W. T. C.-C. (2014). Biological insights from 108 schizophrenia-associated genetic loci. Nature, 511(7510), 421-+. Retrieved from <Go to ISI >://WOS:000339335700037. doi:10.1038/nature13595

Rudic, R. D., McNamara, P., Curtis, A. M., Boston, R. C., Panda, S., Hogenesch, J. B., \& Fitzgerald, G. A. (2004). BMAL1 and CLOCK, two essential components of the circadian clock, are involved in 
glucose homeostasis. PLoS Biol, 2(11), e377. Retrieved from https://www.ncbi.nlm.nih.gov/pubmed/15523558. doi:10.1371/journal.pbio.0020377

Sandin, S., Lichtenstein, P., Kuja-Halkola, R., Hultman, C., Larsson, H., \& Reichenberg, A. (2017). The Heritability of Autism Spectrum Disorder. Jama-Journal of the American Medical Association, 318(12), 1182-1184. Retrieved from <Go to ISI ://WOS:000411769300026. doi:10.1001/jama.2017.12141

Stahl, E. A., Breen, G., Forstner, A. J., McQuillin, A., Ripke, S., Trubetskoy, V., . . Psych, B. D. W. G. (2019). Genome-wide association study identifies 30 loci associated with bipolar disorder. Nature Genetics, 51(5), 793-+. Retrieved from <Go to ISI >://WOS:000466842000007. doi:10.1038/s41588-019-0397-8

Stein, M. B., Chen, C. Y., Jain, S., Jensen, K. P., He, F., Heeringa, S. G., . . Collaborators, A. S. (2017). Genetic Risk Variants for Social Anxiety. American Journal of Medical Genetics Part BNeuropsychiatric Genetics, 174(2), 120-131. Retrieved from <Go to |S|>://WOS:000394957100002. doi:10.1002/ajmg.b.32520

Sudlow, C., Gallacher, J., Allen, N., Beral, V., Burton, P., Danesh, J., ... Collins, R. (2015). UK Biobank: An Open Access Resource for Identifying the Causes of a Wide Range of Complex Diseases of Middle and Old Age. Plos Medicine, 12(3). Retrieved from < Go to ISI>://WOS:000352096300001. doi:ARTN e100177910.1371/journal.pmed.1001779

Sullivan, P. F., Neale, M. C., \& Kendler, K. S. (2000). Genetic epidemiology of major depression: Review and meta-analysis. American Journal of Psychiatry, 157(10), 1552-1562. Retrieved from <Go to ISI >://WOS:000089633900002. doi:DOI 10.1176/appi.ajp.157.10.1552

Tsuno, N., Besset, A., \& Ritchie, K. (2005). Sleep and depression. J Clin Psychiatry, 66(10), 1254-1269. Retrieved from https://www.ncbi.nlm.nih.gov/pubmed/16259539. doi:10.4088/jcp.v66n1008

Turley, P., Walters, R. K., Maghzian, O., Okbay, A., Lee, J. J., Fontana, M. A., ... Benjamin, D. J. (2018). Multi-trait analysis of genome-wide association summary statistics using MTAG. Nature Genetics, 50(2), 229-237. Retrieved from https://www.ncbi.nlm.nih.gov/pubmed/29292387. doi:10.1038/s41588-017-0009-4

Wilson, R. S., Krueger, K. R., Arnold, S. E., Schneider, J. A., Kelly, J. F., Barnes, L. L., . . Bennett, D. A. (2007). Loneliness and risk of Alzheimer disease. Archives of General Psychiatry, 64(2), 234240. Retrieved from <Go to ISI $>$ ://WOS:000243990900011. doi:DOI 10.1001/archpsyc.64.2.234

Winograd-Gurvich, C., Fitzgerald, P. B., Georgiou-Karistianis, N., Bradshaw, J. L., \& White, O. B. (2006). Negative symptoms: A review of schizophrenia, melancholic depression and Parkinson's disease. Brain Research Bulletin, 70(4-6), 312-321. Retrieved from $<$ Go to |S|>://WOS:000241546500007. doi:10.1016/j.brainresbull.2006.06.007

Wray, N. R., Ripke, S., Mattheisen, M., Trzaskowski, M., Byrne, E. M., Abdellaoui, A., . . Working, M. D. D. (2018). Genome-wide association analyses identify 44 risk variants and refine the genetic architecture of major depression. Nature Genetics, 50(5), 668-+. Retrieved from <Go to $|S|>: / / W O S: 000431394900010$. doi:10.1038/s41588-018-0090-3

Wulff, K., Gatti, S., Wettstein, J. G., \& Foster, R. G. (2010). Sleep and circadian rhythm disruption in psychiatric and neurodegenerative disease. Nature Reviews Neuroscience, 11(8), 589-599. Retrieved from https://www.ncbi.nlm.nih.gov/pubmed/20631712. doi:10.1038/nrn2868 